\title{
THE FOUR SYSTEMIC ERRORS OF ECONOMIC POLICY IN SPAIN AFTER THE PANDEMIC: A VALUES PERSPECTIVE
}

\author{
Author(s) / Auteur(s) : \\ Francisco PARRA-LUNA \\ Catedrático Emérito de Sociología UCM jubilado; Miembro de la International Academy for Systems and \\ Cybernetic Sciences (IASCYS); Vice-presidente de la Union Européenne de Systémique (UES); Presidente de \\ Honor de la Sociedad Española de Sistemas Generales (SESGE); Presidente del Centro Internacional "Lugar \\ de la Mancha” de Estudios sobre el Quijote" (CILMEQ); Editor del Boletin AVANCES SISTÉMICOS \\ parraluna3495@yahoo.es
}

\begin{abstract}
Résumé :
The present work tries to demonstrate that, mainly since the emergence of the world economic crisis in 2020 , those responsible (theoretical and practical) for the Spanish economy, have been making four mistakes that are causing an unnecessary delay in getting out of the crisis. These errors would be: first, not having started from an analysis of the Spanish "value system" in which the crisis occurs; second, not having known how to differentiate before the international markets and organizations the specificities of the Spanish system that, because important and unusual, would have allowed economic growth superior to that of the surrounding countries; third, not having developed an integrated and quantified global model with the series of measures proposed; and fourth, to continue being attached to obsolete economic theories that do not give rise to the innovation demanded by the new characteristics of complex societies.
\end{abstract}

Keywords / Mots-clés :

system of values, systemic disconnection, systemic 'sin', axiological imbalances, unused resources

\section{INTRODUCTION}

If we have to rethink the world after the Coronavirus Pandemic, we have no other issue that to describe the systems of values in which we live and the system of values in which we would like to live. Although few colleagues seem to assume this determining postulate (Karl W, Deutsch in Political Science and Mario Bunge in Philosophy are exceptions), I do not think that is correct to avoid this axiological point of view, since its non-application inevitably leads to spurious or false results. And even if we do not call this approach "axiological" and call it "ecological", humanistic, "philosophical" or others, it would be necessary to refer to a close system of universal human needs and the corresponding values that satisfy them. From a human perspective, we cannot escape this model, since from the time we wake up in the morning until we fall asleep at night, we cannot stop being occupied by one o more of the nine values of our model (see table 1 below), even it we are not aware of it. And forgetting this requirement can cause spurious results. The value approach is so general, that offers the possibility of using it for small personal circumstances or for big universal problems. In the case that follows it will applied to the problematic and especial situation of Spain where the social effects of the coronavirus pandemic, together with a high level of unemployment, announces a very acute economic crisis.

Therefore, what I will present are the results of an axiological systemic model to reduce unemployment in Spain, but starting with the presentation of the main mistakes committed from a systemic perspective in Spain.

Nevertheless the first question is: can a systemic-cybernetic perspective criticize the economic policy applied lately in his country? It seems clear that complex phenomena, such as the current pandemic and economic crisis, should be viewed not only by specialized professionals (epidemiologits and economists), but also by other scholars and from different perspectives. A Spanish doctor, José de Letamendi, has already told us: "who only knows medicine, does not even know medicine". Thus, an 
"axiological" analysis (to deal with "values"), necessarily carried out by any multidisciplinary team with an integrating vision, could shed new light and make us understand the true substance of the economic crisis. Although for this, it is necessary to establish some prior methodological requirements in order to understand the Spanish problem.

The first is to define a valid "Comparable International Space" (CIS) to place Spain where it belongs. It is known that there is nothing big or small, good or bad, rich or poor, but "in comparison with ...". Spain, then, needs to be compared to a group of countries that, by level of development, geography and history, serve as a mirror in which to look, or as a sociological "reference group" to which we want to be like. Group of countries valid for systematic comparisons, to avoid comparing ourselves with the country that interests us the most, which unfortunately abounds. I therefore propose that the ICS for Spain be made up of the following ten countries: Germany, France, United Kingdom, Italy, Netherlands, Belgium, Sweden, Austria, Denmark and Finland. A minimum scientific rigor in any analysis requires this measure, whatever the place that Spain occupies.

\section{THE SPECIFIC SPANISH PROBLEM BEFORE AND DURING THE PANDEMIC: THE FOUR MISTAKES OF THE SPANISH ECONOMY}

Going into the matter and as we well know, Spain had, for decades, been a real statistical embarrassment due to its high level of unemployment. While in the other indicators (trade deficit, economic growth, inflation, debt,.... Spain is in the line of the other comparable countries. The scandal is due only by the unemployment rate.

Why the level of employment is so high? For what reasons do Spanish economists seem unable to correct it as their colleagues in the ICS countries have? I have friends who are economists who do not want to seem daring, but my personal hypothesis is that, apart from some circumstantial factors, the Spanish economists have been formed and educated in the neoliberal principles of the economic science, mainly under the influence of the USA universities. The problem, then, is to see the object with the glasses of only an specialized school of thought and performing the four main errors that have been made for several decades, namely: not starting from the "value system" that explains the economy; not to assert the "Spanish difference" before organizations and markets; not to propose a quantified global model; and remain anchored within an obsolete theoretical scheme. I will try to explain them briefly:

\section{FIRST MISTAKE: DO NOT START FROM OUR "VALUE SYSTEM"}

From a necessarily humanistic perspective, there does not seem to be anything more important than locating our economy within the "value system" in which we live. What needs a little introductory explanation about the origin of the axiological approach. To do so, it will be necessary to come back to the theories of human needs if we agree with the anthropologist C. Kluckhonn ${ }^{1}$, when he states that "value is only the reverse of the medal of need". Needs that, at least since Maslow in the 1970s, were listed in his well-known scheme: Physiological, Security, Affiliation, Recognition and Self-realization, initial list of universal human needs that, although incomplete, has been serving as a theoretical basis for further developments. Logically, since the beginning of the ideas about a first Natural Law with Aristotle, Cicero and others...., And later others such as Tomas de Aquino and Francisco de Suarez from the 13th century, universal human rights were outlined, which, in addition to giving rise to to modern Axiology (the science of the "good" or "valuable") with Ehrenfels, Meining and Brentano ..., followed later by Max Scheler and Robert S. Hartman among others, ends modernly taking official and political body with the Universal Declaration of the UN Human Rights in 1948, as well as by later more recent theoretical contributions (Laswell and Deutsch in Political Science, the movement of

\footnotetext{
1 C. Kluckhohn, "Values and Value Orientations in Theories of Action," in Parsons, T. and Shils, E. "Theory of Social Action," Evanston, Illinois, 1961. The importance of values in the world is implicitly highlighted by "The Economist" March 26th 2011, in several of his works. See: "Where will it end?"; "A crisis of leadership, too"; "Not so fast, Ma Bell" and "Another year of living dangerously"; and prof. Pulido San Roman brilliantly describes the problem of freedom / economic growth through his theory of the three hands: the classic "invisible hand", the "correcting hand" and the "support hand", in "Travels by Econolandia", Piramide, 2002.
} 
social indicators in Sociology with Bauer and Gross, von Neumann and others in Economics, Rawls in Philosophy, and In general, all the authors who have subsequently addressed the issue of social needs / values such as Doyal and Gough ${ }^{2}, \mathrm{Heller}^{3}, \mathrm{Mendez}^{4}$, and van-Neef ${ }^{5}$, among whom I modestly find myself $^{6}$. Specifically, the scheme with which I have been working, a kind of summary of the previous contributions, is made up of the following nine values of a universal nature in response to the respective universal "needs" of the human being: Health, Wealth, Security, Knowledge, Freedom, Distributive Justice, Conservation of Nature and Quality of Activities, where each one of them can be operationally represented through several theoretical dimensions and at their turn each one represented by several empirical quantitative indicators. For instance, the value of Health can be divided into the dimensions of Life Span, Quality of Life and Health Safety. And the Life Span can be measured by Life Expectancy at Birth; the Quality of Life for days lost from work and Health Security for Hospital Beds and medical o paramedical personnel.

Although each of these nine universal values can be represented by hundreds of indicators, for simplicity, table 1 shows the particular case where the Values are represented by one single empirical indicator.

Table 1: A Reference Pattern of Universal values.

\begin{tabular}{|l|l|}
\hline VALUES & EMPIRICAL INDICATOR \\
\hline 1.Health (S) & Life expectancy at birth \\
2. Material wealth (RM) & Per capita income \\
3.Security (Se) & Unemployment Benefit (\% GDP) \\
4. Knowledge (C) & Patents registered per million inhabitants \\
5. Freedom (F) & Index of liberties (Tax Pressure) \\
6. Distributive Justice (JD) & Unemployment (\% employed population) \\
7. Conservation of Nature (CN) & Environmental Performance Index \\
8. Quality of Activities (AC) & Unemployment (\% employed population) \\
9. Moral Prestige (PM) & Public Debt (inverse\% of GDP) \\
\hline
\end{tabular}

These nine values form what I call the "Reference Pattern of Universal Values" (RPUV) whose two main characteristics are: first, they must include any appetite, need, impulse or desire (good or bad, rational or irrational, natural or artificial) that a human person may feel in no matter what time and space; and second, that they form an interrelated system where any variation in one of them affects the others to a variable degree. It is therefore a matter of listing a limited number of universal needs / values that are deeply rooted in the concept of natural law from which they originate, compared to the innumerable quantity and variety of needs / values that the world is and that we would call "cultural". Pattern of universal values whose only role is to measure the "quality of life" of individuals, peoples and societies and without which it would not be possible. Although it is assumed that all the nine values interact with each other, and efforts are made to operationalize each value by means of its own empirical indicators, it should be noted that unemployment, given its enormous relative weight, inevitably stands out, directly and negatively affecting both Distributive Justice and Quality of the activities. Unemployment, at the level at which it occurs in Spain, results in a "super-indicator" whose severity is specified by placing it in surveys as the first national problem

\footnotetext{
${ }^{2}$ Doyal, L. and Gough, I, "Theory of human needs", Icaria, Barcelona, 1994.

${ }^{3}$ Heller, A., "Theory of the needs in Marx", Ed. Peninsula, Barcelona, 1978

${ }^{4}$ Mendez, J.M., "Theory of value", Estudios de Axiología, Madrid, 1988.

${ }^{5}$ Van Neff, M., "Development on a human scale: concepts, applications and reflections", working document, CEPAUR, Chile, 1993.

${ }^{6}$ See, eg, F. Parra Luna, "Organizations and their value systems", Documentation Bulletin of the Fund for Economic and Social Research, Conf. Esp. De Cajas de Ahorros, vol IX, fasc. 3, July-September 1977. And also "Axiological Systems Theory: Some Basic Hypotheses, Systems Research and Behavioral Science, 00. 1-26, 2001.
} 
Minimally defined both the "Values Pattern" to be used and its function, we deduce the Spanish position based on the available empirical data, which can be done if we place the levels of each country on a $0-100$ standardized scale for all the values. The level "100" will then be awarded to the country with the best data and " 0 " to the country with the worst, with the rest of the countries placing them proportionally within this common range. Thus, in the value "Health" (S) (Fig. 1) level 100 corresponds to the ICS country with the highest "Life expectancy at birth" (in this case France with 80.98 years) and " 0 " to the country that occupies the last place. (Denmark with 78.30 years) and with Spain in a relatively high position (80.05 years). While in the "Material Wealth" value corresponds 100 to the Netherlands $(\$ 40,718)$ and "0" to Italy $(\$ 31,909)$ and with Spain in a low position (\$ 32,545 ) and close to Italy, and so on with the nine values and their respective empirical indicators. It is, therefore, to place the relative position of Spain among the ten countries of the ICS, value by value, or indicator by indicator, which according to the data handled ${ }^{7}$ provides the axiological profile of fig. 1.

\section{SPANISH VALUE SYSTEM}

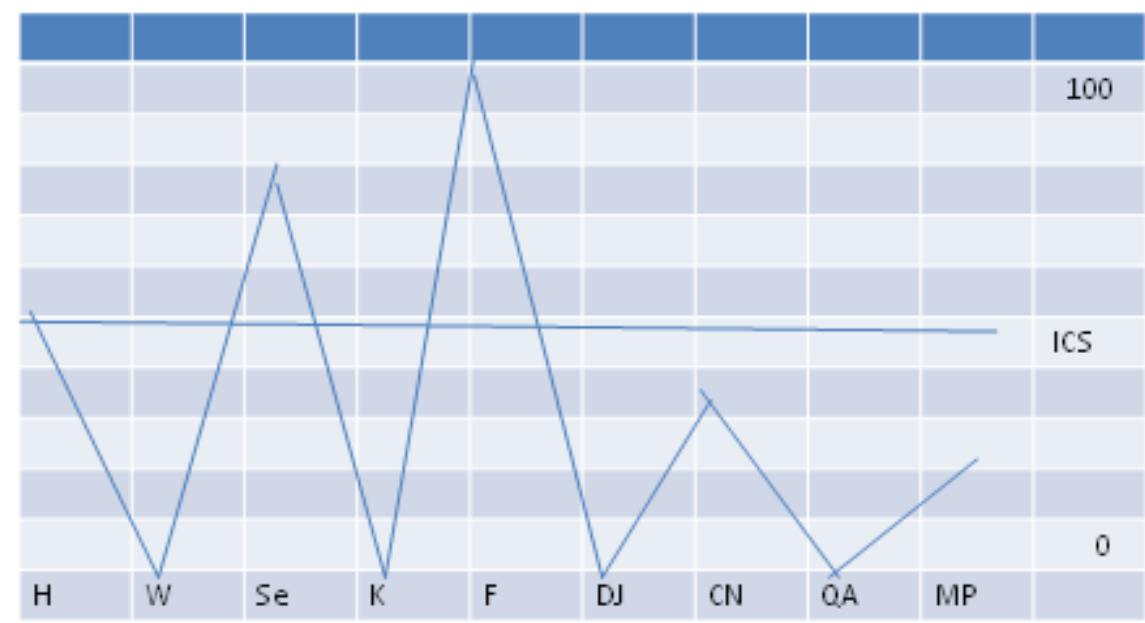

Figure 1. The Spanish "System of Values" compared with ICS countries.

What is the used of this "axiological profile" or SYSTEM OF VALUES? For the moment limiting the operational definition of each of the values to its most relevant indicator, fig. 1 shows how Spain occupies a very low position (penultimate) in "W" (Material Wealth) and absolutely the last in "K" (Knowledge -Patens-), "DJ" (Distributive Justice -GINI Index-) and "QA" (Quality of Activities Unemployment-), these last two due to work stoppage. Global position that defines a highly unbalanced "value system" within the ICS context, and although it would be relatively well placed in "Health" (H) dut to its "life expectancy", and "Security" (Se) due to the unemployment benefits; and relatively in Moral Prestige (MP) due to public debt, little aid to developing countries and some arms exports, the imbalances are evident.

What can be done with this profile? How then can the economic crisis in Spain be attacked? How could it be possible to "horizontalize" and raise the profile at the same time knowing that this would be the only serious and true way out of the crisis? Or perhaps is it thought that an economy can be managed without having this profile in sight? The extreme positions that Spain marks are indeed

\footnotetext{
7 Data obtained from: World Economic Forum, The Global Competitiveness Index, 2010; Transparency International: Global Corruption Report 2009; Freedom House: Freedom in the World, 2011; International Monetary Found, World Economic Outlook, 2011; E.U. European Commission. Eurostat Statistics, Sustainable Development Indicators, 2010; OECD, Main Economic Indicators, 2010; OECD Statistics, Countries Statistical Profiles, 2010; and The World Bank Development Indicators, 2011, Environmental Performance Index, Yale \& Columbia Universities, 2010; OECD Labor Statistics, Unemployment benefits, 2010; CIA World Factbook 2009; The Economist 2011; and Fraser Institute, Index of Economic Freedom, 2010.
} 
suggesting measures quite different from those that are usually recommended or adopted. Because ultimately the correct question would not be: "What economy do we have?", But what society do we have? Here is the key to the problem.

It would be undesirable then to go ahead without visualizing this profile, despite the fact that practicing economicism only seems to be concerned to see if it comes out of the crisis in $\mathrm{L}$, in $\mathrm{V}$, in $\mathrm{U}$ or in $\mathrm{W}$, but only in that way (important as it is ), we do not know where we are going, nor will we know how to overcome the current coronavirus crisis. It seems, therefore, clear that the strategy must consist of raising the "Material Wealth" values (dealing with economic growth, but through job creation given the structure of the profile); "Knowledge (promoting invesigation and the educational and training systems); Distributive Justice (reducing unemployment, exaggerated wages and bonuses, and through tax reform progressive); and "Quality of Activities, (reducing unemployment and increasing participation in work). And all this at the cost of savings (lower levels) in the values "Health (eg, co-payment of certain services and medications); Security (reduction of unemployment benefit); Freedom (reduction of the shadow economy, tax fraud, corruption and other regulatory deficiencies) and Moral Prestige (Increasing public debt if necessary, given our position in the profile). These would be, in summary, the fundamental changes that an axiological profile such as the Spanish suggests (and inevitably would require), and this without proceeding for the moment to weigh the values and indicators with different weights, but whose operation would not be a problem. Threfore, it is about rebalancing the profile, horizontalizing it and raising it at the same time as pursuing that the area under it to the abscissa axis is enlarged. There would be no better possible policy.

This being the case, what deep meaning would the current crisis have beyond the usual economic difficulties? Wouldn't we rather be facing a problem of method and design? Wouldn't it be more convenient to change the classic economistic function "Unemployment $=\mathrm{f}$ (Economy) that expects to grow by $3 \%$ GDP to start reducing it; and instead adopt precisely its inverse, that is: Economy $=\mathrm{f}$ (Unemployment) to make job creation the independent variable on which to act ?. Because if we trust in having a European unemployment rate applying the first formula we can already wait sitting down. Wouldn't it be more logical to show objective (demonstrable) needs to create jobs since we have money that is misused (demonstrable)? And deep down, wouldn't the problem be more ethical than economic? For example, is it morally and functionally acceptable that the required degrees of freedom and deregulation are granted so that cases such as those of Gescartera, Ballena Blanca, Marbella, Forum-Afinsa, Palau, Gurtel, CAM, Andalucia, millionaire salaries and bonuses in the Banking and so many other excesses, can they occur?

And can a country come out of the crisis when politicians seem to think more about their personal positions than the voters who elected them? And can politicians have the necessary theoretical and methodological instruments when the same technicians would adopt, apparently out of sheer comfort or laziness, economic principles that are obsolete or unsuited to the current crisis in Spain? It is explained that with such a low technical and moral profile dominating our economic structure, we present the embarrassing credentials of having the highest level of unemployment to the international press. If we want to get out of the crisis at the same rate as the ICS countries, or at least understand the deep nature of our crisis, the first thing we would have to do is prepare our axiological profile and discover why we are not able to balance and elevate it as and when. as they have, eg, the Scandinavian countries (fig. 2). It is true that this implies a certain effort: the one that begins with the humility of recognizing the limits and insufficiency of the economical approach to use to understand and overcome the crisis.

And what is more decisive: it is necessary to define the concept of PROGRESS, analyze its dimensions, calculate its level and foresee and design its stages. Without this notion clearly assumed, the economic subsystem cannot play the great role that it could have within the "Value System" of each modern society. 


\section{Etapas hacia el progreso}

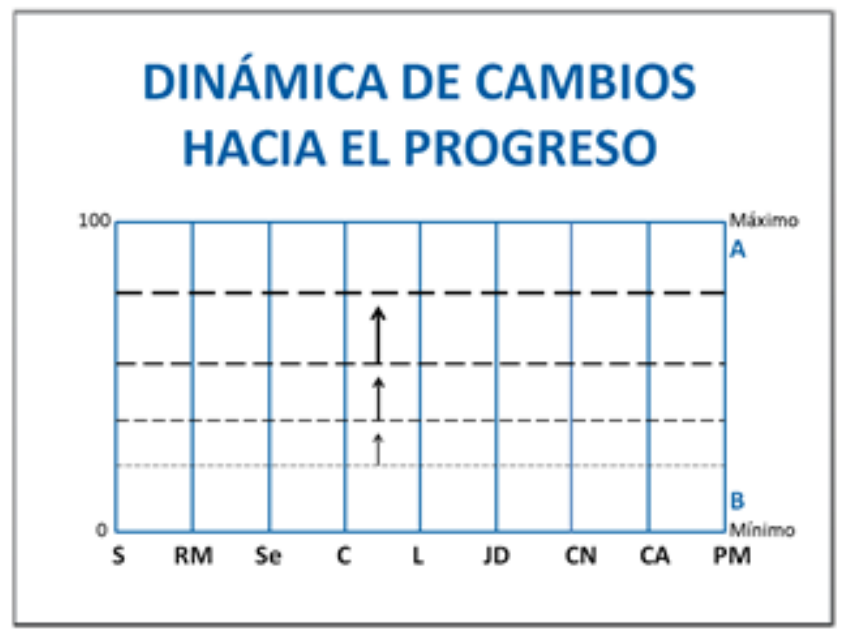

Figure 2. Steps toward PROGRESS.

\section{SECOND MISTAKE: FAILURE TO PRESENT THE DIFFERENT "SPANISH SYSTEM" TO THE EUROPEAN UNION (EU)}

This second error is as serious in the short term as the first. Suffering such exceptionally high unemployment, our economic policy should not be limited to merely following the rules issued by the $\mathrm{EU}$ or other foreign bodies. When ICS countries experience unemployment rates ranging from 6 to $8 \%$, and when they also enjoy higher per capita income, it is understood that they can continue to pay even higher unemployment benefits. But when you suffer a $20 \%$ rate and with a lower per capita income, and when small companies and businesses are closed every day, even reducing the meaning of that average that we call "per capita income", and when young people despair and more than $60 \%$ of the unemployed think of leaving the country, and when, due to unemployment statistics, we are the European embarrassment, and when we are perhaps the country in the world hardest hit by the COVID19 pandemic, ....then something more must be done, much more than is advised by international organizations that do not usually leave the well-known "orthodoxy " to facilitate layoffs, reduce public spending and reduce debt. Because these measures may be appropriate for these countries, but insufficient and even counterproductive for Spain, which clearly presents different and more serious imbalances.

Because not only do we suffer this decisive difference in unemployment, but we add two more. The first is to verify a huge number of "pro-competitive" or technological jobs that are potentially vacant in our country, which precisely explains our negative trade balance due to poor competitiveness and in particular the traditional deficit in our balance due to royalties and patents, whose sales have barely covered $30 \%$ of purchases for this concept. And the second is to spend huge amounts of money, given to the unemployed about 20.000 millions/year in exchange for doing nothing, among other wasteful chapters such as excessive public spending, regional waste, tax fraud, underground economy, obsolete subsidies, etc. This triple imbalance of our Value System (Unemployment, Needs, Dilapidation) comes to represent an "unsustainable triad" of irrationality that does not occur at such levels in any country, not just EIC, but the world. And the reader only have to look at the international statistics to verify it.

And finally, a new decisive difference: not seeing that our problem is growth, not debt. They accentuate us from abroad, and we submissively accentuate ourselves by repeating that our level of indebtedness (public or private) is the cause of our ills, when there are no objective reasons for it, 
since Spain is in better conditions that some of the other ICS countries ${ }^{8}$. And this inability to differentiate ourselves has severe consequences because something is very clear: with economic growth, debts are amortized, without economic growth they grow. And so authorized voices begin to recognize it and lately until the $\mathrm{IMF}^{9}$.

Let's say in passing that just by taking advantage of the triple difference of the Spanish system with respect to the ICS group, the Axiological SETCU model, initially planned for the 2009-2013 period, but applicable at any time, advances the possibility of growing by an average of almost a 4\%of GDP during the next four years as we shall see below.. The secret lies in the proper systemic interconnection between the three differences: unemploment; pro-competitive needs; and squandered money, and logically from the inevitable axiological perspective.

\section{THIRD MISTAKE: DO NOT PROPOSE A QUANTIFIED SPECIFIC MODEL OF THE SPANISH SYSTEM}

The dominant economicism does not seem to be able to present the multitude of measures taken, suggested, or enunciated as necessary, within a quantified global model of economic policy. And that in the short and medium term, sufficiently integrated theoretically and, of course, ideologically at the same time, which is stated in a way that is convincing enough to provide the degree of confidence that the country needs. We already know the good number of measures adopted by the government that, as it can be seen, have not changed nor does it seem that the high level of unemployment will change in the desired period; and even greater is the number of measures of all kinds that are proposed by organizations and scholars in Spain (100 economists, FAES, FEDEA, Círculo de Empresarios, Trade Unions, Fundación Ideas, collective "Ganar 2012", etc.) all of them logical and surely successful if we consider them individually, but first, enunciated in the typical and ussless form "we have to...", (without quantifying) and second, without any theoretical link with the rest of the essential variables of the system and even less with their calculated final effects. But the measures, to be taken seriously, would require at least three requirements: they must be interrelated in a previous theoretical model, quantitatively estimated, and above all, their influences in a global model that demonstrates their viability and balance must be quantified. Or in more direct words: try to calculate before proposing any measure.

Is this triple operation so difficult since it is not formulated by any part? Is not the cause a question of method?. See e.g. the following script in five steps: 1, form a multidisciplinary and inter-ideological team; 2, define the "value system" on which the crisis is based; 3, design un interrelated system of measures to be taken; 4, estimate them quantitatively; and 5, simulate them within the appropriate model and calculate their most probable results. Phases that can also be technically agreed by means of the "forced intersubjective agreements" that allows a methodology like Delphi ${ }^{10}$. But it does not seem that current economism is interested in the global models that any rational planning in the short or medium term demands. And it is that since the failure of the Soviet five-year plans, many times it tends to "throw the child with the bath water." What is strange and at the same time hopeful, is that some notable economist (eg, Cristobal Montoro), has recently come to say that what is needed is a clarifying "scorecard". Blessed is this instrument if it refers to the "systemic-axiological", that is, to the presentation of a new profile projected in response to that of fig. 1 and also developed in its main indicators within each value. Because this is another of the goals that are missing: knowing where we are going as a national society .

\footnotetext{
8 See my article in Business \& Lifestyle, 04/13/2011, "What Spain needs is a regeneration".

9 D. Strauss Khan, Speech at George Washington University on 4.04.2011.

${ }^{10}$ Developed by the Rank Corporation in the 1950s. See recent developments in Scott G., "Strategic Planning for High-Tech Product Development, in Technology Analysis \& Strategic Management, vol. 13, n.3, 2011.
} 


\section{FOURTH MISTAKE: CONTINUE APPLYING AN OBSOLETE THEORETICAL SCHEME ON THE UNEMPLOYMENT-ECONOMY RELATIONSHIP}

Finally, and as is known, neoliberalism continues to enhance people's freedom by thinking that they are thus more productive for the general good of society, and surely with good reason, but it tends to forget two systemic principles: first, the strategic-causal ordering of the variables (f.i., the level of unemployment does not depend on the economy, but the economy depends on the level of employment); and second, the influence of the rest of the social, ecological, ethical and other variables are undervalued (f.i., that it redistributes income worse, pollutes the environment more. , causes bumps and unacceptable financial scandals, and is powerless before the economic crises that the same neoliberal principles produce, thus ending up presenting an axiological profile very similar to that of fig. 1). This is a kind of "single thought" that was assumed by the economic-financial powers since the hecatomb of the Soviet Union and that is permeating the academic-institutional chain responsible for the current economy "urbi et orbi". What transpires, on the part of scholars, in a general apathy towards theoretical innovation and towards an innocuous conformism that qualifies as "orthodox" some principles of said thought stated as religious mantras (eg.: his criticism of labor rigidities and spending public), and of "heterodox" those who propose new approaches (eg, a functional relocation of the money supply ${ }^{11}$ or a new modeling by "complex systems" ${ }^{12}$ ). Logically, there is no lack of critical literature both abroad ${ }^{13}$ and among national economists ${ }^{14}$ in the face of this theoretical conservationism. And since there are notable cracks in this thinking, Spanish economists concerned with the level of unemployment may well dare to critically review their theoretical approaches, but it seems that the power of the institutions that inspire or finance their activities (large Banks and Companies, Universities, Study Institutes, Foundations, Mass Media, etc.) exert such a veiled and efficient pressure on their wills that they silence any attempt at theoretical rebellion, whether they are engaged in financial analysis, econometrics, economic history or merely commenting of data and trends. And it is that from the perspective of these power centers, you are either with them or against them.

And the result, until the spring of 2020, before and during the Coronavirus pandemic, is that we continue as locked in the triangle of model $\mathrm{A}$ in fig. 2, where routine economism can only provoke a theoretical inertia that in turn implies the corresponding institutional inertia to end up feeding back the delay in coming out of the crisis. In other words, a full-fledged vicious circle. Think the reader how you can get ahead, e.g. the Greek economy, inspired by the "economic criteria" that the so-called troika (IMF, EU, ECB) requires of it, because if you think about it, with the internal demand contracted by sacrifices of all kinds, with limited export capacity and with high interests at pay up, the answer is probably: not possible. And subject to the logic of this impoverishing theoretical circuit, although to a different degree, other countries are and still are.

\footnotetext{
${ }^{11}$ F. Parra Luna and J.I. Ruiz Rodriguez, "To get out of the crisis: a quantified model towards job creation", Ed. Del Serbal, 2010; and also F. Parra Luna, "El Paro Permitido", Ed. Coronaborealis, 2010.

${ }^{12}$ Within the movement of the modern economy of complexity, it is worth highlighting the work of Beinhocker, E., "The Origin of Wealth", Harvard Business School Press, ISBN 978-1-4221-2103-0. Likewise: Durlauf, S.N. "What should policymakers know about Economic Complexity? ", wp 97-10-080, Santa Fe Institute, 1997, as well as: Durlauf, S.N., Arthur W.B. and Lane, D. "The Economy as an Evolving Complex Systems II", Redwood City: Addison-Wesley, 1997. See also: Pavard B. and Dugdale, J., "The Contribution of Complexity Theory to the study of socio-technical systems", New England Complex Systems Institute, electronic journal., 2000.

13 J.Stiglitz, "Stability and Growth: Macroeconomics, Liberalization and Develepment, ISBN 84-306-06 15-7,2006; and also P. Krugman, "The Return of the Economy from Depression, Ed. Critica, 2009. 17. A. Anchuelo and M.A. Garcia, "The economy built on sand," Esic, 2009, and also J.F. Martin Seco, "What are we economists for?", Catarata, 2010.

${ }^{14}$ J. Juan, Nada es gratis, Ed, Destrino, Barcelona, 2011; y A. Martinez Estevez y V.J. Pallardo López, Los Siete Pecados de la Economía Española, Ediciones Nobel, Oiedo, 2013.
} 


\section{Two theoretical models to face the economic crisis}

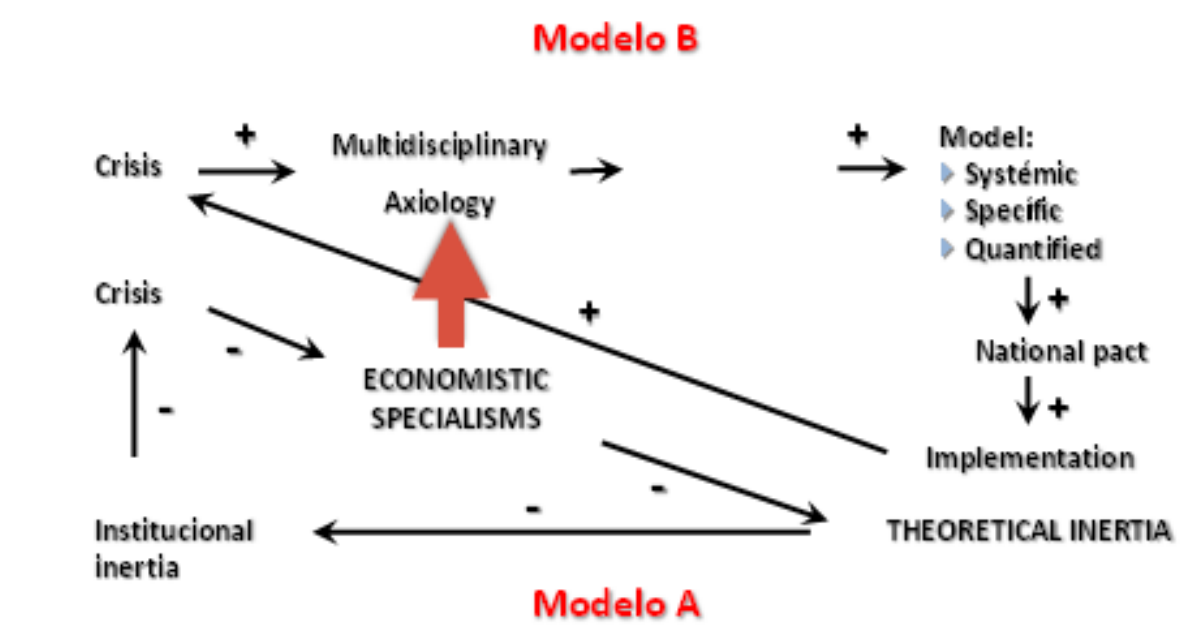

Figure 3. Two theoretical economic approaches.

What can be done?. What would be required, on the contrary, as Figure 3 shows, is the humility of recognizing the limits of current economicism (model A), particularly for cases such as the Spanish who fortunately has an "unsustainable triad" (Unemployment, Needs , Financing) absurdly wasted because of its disconnection within the system, and move as soon as possible to a model such as B that will require imagining and innovating new strategies and theoretical-methodological approaches, which allow, starting from multidisciplinary contemplation of "value systems" explanatory of the crisis, proceed to the series of connections and necessary methodological operations (systemicity, specification and quantification) in order to generate, in the population, the CONFIDENCE required, both in the technical model (especially in this one) and in the willingness and ability of politicians to implement it. But it must be recognized that this is such a change in theoretical perspective on the part of the technicians that, rather than effort, it requires certain doses of mental elasticity and ethical humility that sometimes seem to be conspicuous by their absence if we take advantage of certain recent signs.

Allow me the reader, then, a couple of anecdotes that although I have already related in some other medium ${ }^{15}$ come to the case as the famous "glove" of the fool, where neither face was missing nor hand was left over. When a first version of the Axiological-SETCU model was presented to a prestigious economist, an all-powerful former Minister of Economy in his country for several years, asking for his opinion on it, he replied in a very polite way that he felt "not being able to give his opinion for not understanding neither the systemic approach nor the value system used". Truly surprising answer. How can a former Minister of Economy and Finance ignore the systemic method that he practiced so many times giving budget to some ministries what was removed by others? And how can the "value system" be ignored when an endowment to improve, eg, health (Health value), may have been at the cost of damaging infrastructure ("Material Wealth" value) ?. Was it not a continuous political administration of the employer's values? And do not think, reader, that I would be alone in the profession, because another prestigious colleague, professor emeritus, national economics award, told me by telephone that he did not understand the model at all. And another director of the institute of

\footnotetext{
${ }^{15}$ See eg my art. "The economistic blurring of the economy", in BUSINESS \& Lifestyle, 09.02.2011. and also in: "How much do four and a half million unemployed people weigh in Spain?", in NOTARIO del Siglo XXI, n.36, March-April 2011.
} 
economics in the provinces expressed himself in similar terms, and yet another qualified professor who knew the model and its results, silences it in a publication when he wrote precisely about how to get out of the crisis. All of which is worrying, not so much for the model and its authors, but for the almost five million unemployed Spaniards and their consequent chain of negative effects for the entire country. It is true that other qualified colleagues (Cabrillo, Gimeno Ullastres, Requeijo, Barea, Pulido San Román, Casares, Carmona, ...) could also express that they did understand the basic strategy of this Axiological-SETCU model which, basically and to summarize, consists only in relocating the money supply in circulation in our country more rationally.

And there is another sadly significant anecdote about the current state of economic science. When the model was presented with equal humility to another prestigious econometrician for criticism, this one simply disqualifies it for having advanced some calculations in terms of simple proportions. For example, it was adopted that if a GDP of 1 trillion euros is obtained by 20 million active people, it seems acceptable, in principle and in the exploratory terms of the model, that each new job created (on average throughout the pyramid of roles and positions in Spain) would produce 50,000 euros of annual GDP, although this average was subsequently modified in the model by other coefficients. In short, it seems as if orthodox economics (current econometric approaches) amuse itself by "killing flies with cannon shots".

\section{TOWARDS A NEW QUANTITATIVE MODEL}

One of the concerns of the author in the development and presentation of the model has been its clarity and simplicity. The good, if it is good, must be understood and accepted by the greater number of readers possible. As a Heinsenberg said: "For a scientist, the description in plain language, is a measure of the degree of understanding reached. ${ }^{16}$ Hopefully it is fulfilled in this chance as table 2 shows:

Table 2: The logic of the Values-SETCU Model.

\section{MODEL JUSTIFICATION}

This model presents an overwhelming logic based on the following principle that should be rise to few doubts: If a government withholds the amount " $x$ " paid as unemployment benefit to each of the unemployed "y" persons, to provide them with productive work that generates individual GDP "z", will always happen that zy> xy, thus demonstrating the profitability of the operation, apart from the known psychological, social and political advantages of being busy versus standing. The highly probable inaccuracies or the oversized calculations that follow should be secondary and perfectly corrected. It is only necessary to verify three facts: if there is excessive unemployment; if there are unmet needs; and if there is money wasted. Three excesses that are quantifiable and verifiable by anyone who takes the trouble to do it.

The phases and calculations of the Model by Values-SETCU can be seen in AVANCES SISTÉMICOS n. 9, November 2020. Tables 3 and 4 summarize its results;

\footnotetext{
${ }^{16}$ Science Profiles. Principe Felipe Science Museum Foundation. Valencia, 2003.
} 
Table 3: Changes on Unemployment due to the "Model by Values-SETCU".

\begin{tabular}{|l|l|l|l|l|l|l|}
\hline Year & $\begin{array}{l}\text { Active } \\
\text { population } \\
\text { (miles) }\end{array}$ & $\begin{array}{l}\text { Initial } \\
\text { unemployed } \\
\text { (miles) }\end{array}$ & $\begin{array}{l}\text { Employment } \\
\text { created by } \\
\text { the model }\end{array}$ & Unemployed & $\begin{array}{l}\% \\
\text { Unemp }\end{array}$ & $\begin{array}{l}\text { Observations } \\
\text { Data } \\
15,6 \% \\
2020 \\
\text { of } \\
\text { according } \\
\text { for de España } \\
\text { to } \\
(44)\end{array}$ \\
\hline 2020 & 21.973 & 3.368 & 0 & 3.368 & 15,3 & 15,6 \\
\hline 2021 & 21.973 & 3.368 & 356 & 3.012 & 13,7 & 14,0 \\
\hline 2022 & 21.973 & 3.012 & 469 & 2.543 & 11,6 & 11,9 \\
\hline 2023 & 21.973 & 2.543 & 132 & 2.411 & 10,5 & 10,8 \\
\hline 2024 & 21.973 & 2.411 & 330 & 2.081 & 9,5 & 9,8 \\
\hline & & & 1.287 & & & \\
\hline
\end{tabular}

Let's now see the contributions of the Model by Values-SETCU in terms of GDP growth, both separately and integrated into the policy that it is assumed to be normal or expected by the Spanish government according to the Bank of Spain's forecasts. The growth expected in parallel to the pandemic COVID-19 and without terminating it, it is estimated in table 4.

Table 4: Changes on GNP and Unemploeyment with and without the model

\begin{tabular}{|l|l|l|l|l|}
\hline Año & $\begin{array}{l}\text { Prev.B.España } \\
\% G N P\end{array}$ & $\begin{array}{l}\text { Prev.Model } \\
\text { \%GNP }\end{array}$ & $\begin{array}{l}\text { Totals } \\
\% G N P\end{array}$ & Observations \\
\hline 2020 & $-11,6$ & 0 & $-11,6$ & \\
\hline 2021 & 6,8 & 0,95 & 7,75 & \\
\hline 2022 & 2,4 & 3,08 & 5,48 & \\
\hline 2023 & $2,4^{*}$ & 4,08 & 6,48 & \\
\hline$\cdot$ & $2,4^{*}$ & 6,90 & 9,30 & $\begin{array}{l}\left(^{*}\right) \text { Sums not comparable by } \\
\text { own estimate of 2.4* }\end{array}$ \\
& 2,4 & 15,01 & 17,41 & \\
\hline
\end{tabular}

These are the summarized results of the model that only pretends to be provisional

"(it will always be necessary to repeat our estimates), and explains (see AVANCES SISTÉMICOS n.9, November 2020) the main steps taken until reaching a predictable final result that, according to first approximations, will consist in round numbers in: lower unemployment to half the current level (from 20.1 expected in 2021 to $10 \%$ in 2024) (42); increase GDP over the 2021-24 period by 17\% (almost 4\% annually as average); reduce the Public Deficit or the Public Debt by 2\% of GDP; as well as getting a broad and satisfactory agreement between Employers and Unions. And above all, what results essential: improve and balance the "value system" for the whole of Spain, which is really important. All achievements as a complementary activity and in parallel to the normal government. 


\section{TO RESET THE ECONOMIC APPROACHES?}

Why this question? Because the results of this model are one thing, and the attitude of a large part of economists, mainly neoliberals, is quite another. Therefore, the most serious and what testifies to the implicit weakness of economic science, is when some reputable colleagues recommend us to read a work (written in English, of course), prepared by three other colleagues from a prestigious foundation of economic studies, whose approximate title was: "MEDEA: A DSGE model for the Spanish economy", by P.Burriel, J. Fernandez-Villaverde y JF. Rubio-Ramirez, and whose precise objectives were: "to describe the main characteristics of the Spanish economy with a view to future economic policy ...". Well, after dedicating 50 of the 71 pages of the document to purely mathematical formalisms (I do not exaggerate), the research fails to discover any of the great imbalances that the Spanish system suffers, especially what we call the "unsustainable triad" composed of " unemployment ", "unmet needs "and" monetary squandering".

What part of professional responsibility corresponds both to these last three authors and to those who did not perceive the role of the concepts "systemic" and "axiological" in our economic crisis? Perhaps not too much, because these attitudes are surely based on having unconsciously mythologized a scientific culture that maintains that if Physics, Chemistry or Biology have triumphed as sciences, it is due to a rigorous use of mathematical language tending also to concentrate on infinitely small. Attitude that I personally share despite the criticisms made by Heisenberg (uncertainty principle), by Gödel (principle of axiomatic inconsistency), and by certain postmodernist, hermeneutical and constructivist positions against current neopositivism. And despite these positions, I have also been defending the quantification in Sociology and Political Science since my first works, as can be seen ${ }^{17}$, but always without going over, trying to weigh the "utility / cost" relationship of the formalisms, adopting rather the "macroscopic" position (Joël de Rosnay) that the social demands, and without coming to the extravagance of recommending readings like that of the last cited work of FEDEA, apparently with the sole purpose of boasting what-is-lacking. Having said this, in case it made us move forward, and based on overcoming those four supposedly committed errors describe above, our multidisciplinary team (made up of 15 professionals: sociologists, economists, businessmen, consultants, engineers, ...), has tentatively and exploratively prepared the Axiological Model-SETCU whose results were summarized above, which projects a faster way out of the crisis and whose process can be seen in two books published in 2010, (15)

That is why, AVANCES SISTÉMICIOS, n. 9, November 2020, is allowed to present two contributions that could be decisive: first, a summary in terms of GDP and unemployment achieved by the action of the model as summarized in tables 3 and 4; and second, a proposal that we call "economic reset" that would transform positively determined theoretical relationships (converted into methodological routines) that currently make it difficult to achieve economies compatible with balanced "value systems", or which is the same: the concept of BALANCE (concept of PROGRESS) seen in fig. 2 ). Therefore, table 5 summarizes six principles toward a possible "reset" of the economy that should at least be revised or criticized:

\footnotetext{
${ }^{17}$ From my first work: F. Parra Luna, "Une méthode pour l'intégration des indicateurs: la I-Distance”, Revue Europeenne des Sciences Sociales, Tome XI, 1973, num. 30. See also "Elementos para una teoría formal del sistema social”, Editorial Univ. Complutense, 1983.
} 
Table 5. A possible "reset· of some economic approaches.

1. Current economic theory should not ignore an essential tool (the REFERENTIAL PATTERN OF UNIVERSAL VALUES or "RPUV") (Table 1) and the axiological profiles that it builds (fig. 1 to 3 ) in its double application: one part, the "Enveloping System of Values" in which any "economic subsystem" is inserted, since the first, conditions or explains the second, by transmitting a large part of its characteristics be they positive or negative. And on the other, the "Value System" of the subsystem under study, which must be compared critically with the first. The world of the nine universal values of the RPUV cannot be marginalized by the same economic institution that so decisively contributes to producing them. There can be nothing more important for Economic Theory than to record the consequences of economic acts on the different "Systems of Values".

2. Current economic theory cannot advance without having a clear idea of the concept of PROGRESS, as it was defined, e.g., in fig. 2. A concept that continues to be one of the main purposes of economic science, in addition to something as intuitive and easy to perceive, as leveling and raising the profile of the "value systems" under study (from fig. 1 to fig. 2). It is then specified by measuring the geometric area that occurs between the profile that defines each "value system" and the axis of abscissa as in fig. 1. It will be the best known way to see if the world (or each system analyzed) progress or regress.

3. "Economic theory should place the necessary emphasis on the negative dialectic between the values of "Freedom" and "Distributive Justice". Recognize that the relative levels reached in these two values are those that ultimately they can enlarge the geometric surface to which the previous point refers (fig. 2), such is the dialectical potential they contain and especially the role they play during the development of any subsystem economic, having to resolve the dissonant balance between "Freedom" to produce and "Justice" to redistribute.

4. Stop assuming that the level of unemployment depends on GDP growth, as when it is stated that "the economy has to grow at least 3\% per year to start creating jobs ", a triply dire dependency ratio: first, because the true functional relationship is precisely its inverse (GDP $=\mathrm{f}$ (Unemployment)); second, because it is $\boldsymbol{\Delta} \mathrm{GNP}=\mathrm{f}(\boldsymbol{\nabla}$ unemployment $)$ focuses on practicing a stark economism regardless of the psychological, social and political consequences of unemployment; and third, for the damage caused to the environment due to the perennial need for developmentalism economic that may not be the one that best suits the balance of the "Value System",

5. Reverse some of the theoretical relationships assumed between various concepts, such as, for example, when it is assumed that the economic development depends on the level of debt, whether public or private, a spurious dependence that only serves to "cry" helplessly over the equation Unemployment = $\mathrm{f}$ (Debt). On the contrary, the positive and empirically functional relationship contrasted, is that of Debt $=\mathrm{f}$ (Unemployment), then setting the action on the explanatory variable as the first link in the chain: $\boldsymbol{\nabla}$ Unemployment $\rightarrow \boldsymbol{\Delta}$ GNP $\rightarrow \boldsymbol{\nabla}$ Debt, since without GDP growth its amortization is not possible, as there will not be enough GDP growth with high unemployment.

6. Dynamically relocate the limits and need for State intervention based on the value system persecuted and its most conditioning environment, instead of focusing excessively on the value "Freedom", when it should do it also and in a balanced way, in the value "Distributive Justice, as well as among others of the profile, such as, for example, of "Quality of Activities" or Moral Prestige. The new economic theory should definitively assume that the State must be at the service of the best possible balance between the 9 values of the profile (notion of PROGRESS) and nothing else.

Table 5 suggests half a dozen ideas that, in our opinion, would be absolutely necessary, although they seem contrary to certain principles of economic neolineralism. Neoliberal principles that due to their pseudo-religious appearance (with the State you must not go even to holy mass), o because phrases like the one pronounced by Ronald Reagan "hello, I'am from the government and I'm here to help" are considered decidedly dangerous for the proper economic functioning (cited by Daniel Lacalle (43)), should however be surpassed as being inappropriate for any scientific approach.

However, what it is convenient to begin, is a strong criticism of the six proposals made, lest they be equally "dangerous". And in any case, let the philosophers decide on the ultimate meaning of economic science, since doctors, and many, undoubtedly have that powerful and "holy" financial structure that supports the best economic and political universities around the world. 


\section{CRITICAL SUMMARY AND CONCLUSIONS}

In the present work, three possible treatments on the Spanish economy have been suggested. In the first, the four mistakes made in economic policy have been highlighted, mainly by not taking into account the "Value systems" in which the economy is inserted; in the second, the final summarized results of the so-called "SETCU Values Model" have been presented; and in the third, six of the measures that would be necessary to change ("to reset") the theoretical and methodological modes in the treatment of economic problems have been enunciated. In this case, all the three suggestions motivated by the high level of unemployment in Spain.

But once more, "Spain seems different". The real problem of Spain in 2013 was not only the economic crisis, especially acute due to its construction bubble. The problem was, and it still is, that their technicians and politicians do not see, or they do not want to see, the real possibilities of Spain to overcome this crisis. More specifically, the crux of the Spanish problem can be described, once again, by the following behavior: those who have the responsibility of steering the country, do not take into account the three main axiological disequilibria ("uncovered competitive jobs", "unemployment" and "financial resources available"), produced at such levels in Spain that they represent an exceptional and unique opportunity in comparison with the rest of developed countries in the world. The key methodological mistake seems to be that these three imbalances are not interrelated at all in practice, whereas a systemic integration of these disequilibria would solve the substantial part of the unemployment problem. In fact, Spain is carrying out, absurdly, an economic policy of disorderly and unused resources. One explanation for this incorrect focus of the problem seems to be: first, that technicians are not ready, either to risk their personal positions before economic powers, or to make the necessary mental efforts to adopt new theoretical approaches to understand the axiological structure of the problem; and, second, the unethical behavior of politicians who usually think more of their personal and electoral interests than of the satisfaction of population's needs. Because, how can it be explained that Spain is capable of being world champion in soccer and at the same time unpresentable "outcast" unemployed? The sum of these two attitudes could be at the heart of the absolutely shameful Spanish unemployment problem, as f.i., can be seen weekly in the Economic and Financial Indicators pages of The Economist. And we should end by admitting again that we can or may be wrong. But let the intelligent reader say if those responsible (theoretical and practical) for the economic policy followed in Spain, mainly since 2008, have been making the four errors described or not. And if they weren't really committing them, we can only apologize to the reader for wasting their time.

\section{REFERENCES}

AXELROD, R. (1997): "Advancing the Art of Simulation in the Social Sciences", Complexity, 3, pp. $16-22 .$.

BEINHOCKER, E: (2006) The Origin of Wealth, Random House, N.Y.

BENDA, J .(2007): “The treason of the intellectuals", Internet,

BUNGE, M .(1980): Epistemology. Science of science, Ariel, Barcelona.

CABRILLO F . (2008): Liberalism and liberalisms, Libertad Digital.com.

CARMONA, A.M .(2003): Economy and innovation, University Library, Londres.

GROOM B .(2008): A fragile flexibility, Financial Times, April 14.

DALLA COSTA, J.(1998). The Ethical Imperative, Harper Business, N.Y..

DURLAUF, S.N .(1997): What should policymakers know about? Economic Complexity, wp 97-10080, Santa Fe Institute, USA..

GELL-MANN, M. (1995): "What is Complexity?", Complexity, vol. 1, n.1.

JAHANBEGLOO, R .(2007): In Praise of Diversity, Arcadia,

KLUCKHOHN, C .(1951): "Values and value orientations in the theory of action", in PARSONS T. AND SHILS, E. Theory of Social Action, F. Press, N.Y.. 
LANGE, O .(1969): Introduction to the cybernetic economy, Siglo XXI, Madrid..

LE MOIGNE, J.L.(2007): Les épistémologies constructivistes, PUF, Paris, .

MASLOW, A . (1970): Motivation and Personality, Harper \& Row, N.York

MATEOS DE CABO, R. \& OLMEDO FERNÁNDEZ, E .(2009): Implications of Deterministic Chaos, Economy and Business Management, .

MAX-NEEF, M .(1993): Development on a human scale, typewritten document.

PARRA-LUNA F. AND MONTERO DE JUAN, J. A .(1989): "Cybernetic Approach to Reduce Unemployment in Spain", Kybernetes, The International Journal of Cybernetics \& General Systems, MCB Univ. Press, vol. 18, num. 5.

PARR-LUNA, F .(2001): “An Axiological Systems Theory: Some Basic Hypotheses", Systems Research and Behavioral Sciences, 18.

PULIDO SAN ROMÁN A. AND PÉREZ GARCÍA, J .: Econometric Models, Pirámide, Madrid. REQUEIJO, J .(2009): Odyssey 2050: The world economy of the 21st century, Alianza, Madrid TOMMASOLI, M .(2003): Participatory development, Iepala, Madrid. 
